\title{
Attitudes towards cheating behavior during assessing students performance: student and teacher perspectives
}

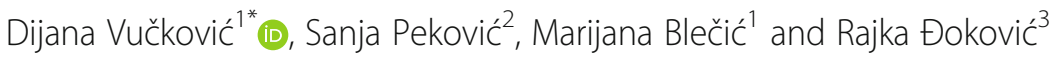

\author{
*Correspondence: dijanav@ucg.ac. \\ me \\ ${ }^{1}$ Faculty of Philosophy, University of \\ Montenegro, Cetinjski put bb, \\ Podgorica, Montenegro \\ Full list of author information is \\ available at the end of the article
}

\begin{abstract}
Our aim in this study was to determine students' and teachers' attitudes towards cheating in assessing students' performance. We used mixed methodology and the main research method was a case study. We aimed to describe how our respondents: 1. recognize ethical misconduct (EM) in several situations given through case studies, 2. understand the roles of each subject involved, 3. predict consequences of the EM and how they understand its possible causes, 4. create individual answers to EM or resolve problem situations. The research sample of students (120) includes participants from three basic study programs and two postgraduate programs in the field of education. A sample of teachers (42) was obtained from a number of faculties by random selection. Our respondents have identified most forms of EM reasonably well, although in some situations, the respondents recognized other errors (poor organization of time for learning, professors' strict deadline for paper submission, etc.) as EM. Therefore, the issues of ethics are not completely clear to all respondents, which leads to the conclusion that universities must organize training in this field. Both groups of respondents understand EM in a similar way, and whether it is a professor or a student (or students) who commits EM has not affected their responses. Our results suggest that it is necessary to work on the prevention of fraud by discussing the consequences (especially the long-term ones, which were not considerably discussed in the comments), by learning ethical reasoning, by developing functional strategies of learning for the purpose of preventing fraud.
\end{abstract}

Keywords: Academic integrity, Causes of cheating, Cheating, Consequences of cheating, Non-ethical behavior

\section{Introduction}

While ethical misconduct (EM) has been studied at world universities since the 1990s (McCabe et al. 2001), it has become a popular topic in Montenegro only in recent years. This does not mean that various forms of EM have not been noted in higher education (ETINED Council of Europe Platform on Ethics, Transparency and Integrity in Education, 2018). Ethical misconduct in (higher) education in a country

(c) The Author(s). 2020 Open Access This article is licensed under a Creative Commons Attribution 4.0 International License, which permits use, sharing, adaptation, distribution and reproduction in any medium or format, as long as you give appropriate credit to the original author(s) and the source, provide a link to the Creative Commons licence, and indicate if changes were made. The images or other third party material in this article are included in the article's Creative Commons licence, unless indicated otherwise in a credit line to the material. If material is not included in the article's Creative Commons licence and your intended use is not permitted by statutory regulation or exceeds the permitted use, you will need to obtain permission directly from the copyright holder. To view a copy of this licence, visit http://creativecommons.org/licenses/by/4.0/. The Creative Commons Public Domain Dedication waiver (http://creativecommons.org/publicdomain/zero/1.0/) applies to the data made available in this article, unless otherwise stated in a credit line to the data. 
experiencing transition ${ }^{1}$ where the education sector is facing a series of reforms represents a most serious disruptive factor to progress. Since there was no research on cheating in assessing students' performance in Montenegro, we considered it necessary to determine from the outset whether there has been a common understanding of cheating, its causes and consequences. We wanted to find out the implicit ethical norms of our respondents (Colnerud and Rosander 2009). Our aim in this study is to determine students' and teachers' attitudes towards academic integrity (AI) issues in assessing students' performance.

We will first present an overview of literature relevant to our research, which also refers to the recognizing and understanding of EM, its social and individual causes and effects, as well as the role of teachers, students and institutions in the prevention and sanctioning of cheating. The results of an empirical research study with students and teachers as respondents follow further on. We have used the case study method, where the respondents evaluated ethical problems presented in case studies.

\section{Literature review}

\section{Fraud in assessment - do we consider the same meaning?}

The question posed by Ashworth et al. (1997), which refers to determining the meaning of the term academic fraud, is still relevant. The authors point out that the term does not have the same meaning for all members of the academic community, while the starting point in various studies is that there is a consensus on the meaning of the term fraud (Ashworth et al. 1997). Even though the problem is a complex one and while it is quite possible that some students may have difficulties understanding its meaning (Trautner and Borland 2013), some authors think that students most certainly know what is expected from them (Burrus et al. 2013). Respondents answer the question What do students perceive to be plagiarism/cheating? correctly and precisely (Jones 2011), e.g. the majority of students knew what plagiarism/cheating is. What we understand by the term cheating in this paper is "Actions that attempt to get any advantage by means that undermine values of integrity" (Tauginiene et al. 2018, p.12), while we will be focused on cheating connected with the assessment of students' performance.

If students have been accustomed to fraud during their previous education and if they live in transitional societies where there is no coherent system of values (Hrabak et al. 2004) - which is the case in Montenegro - then it is quite natural to "mix up" the notions of what is allowed, and what is not. For example, the research conducted by Hrabak et al. (2004) with medicine students (who study ethics as a separate subject) showed that most of them (94\%) admitted to cheating in exams, while almost half of respondents would never report cheating. The knowledge of ethics did not appear applicable to this group of students.

\footnotetext{
${ }^{1}$ Montenegro was part of the united state of the South Slavic peoples, whose last name was the Socialist Federal Republic of Yugoslavia (SFR Yugoslavia), for most of the twentieth century (from 1919 to 1990). After the 1990s and the civil war in the territory of several former members of SFR Yugoslavia, Montenegro remained in a state union with Serbia until 2006, when the population voted for state independence through a referendum. After the restoration of state independence, Montenegro expressed its commitment to European and transatlantic integration, so it joined NATO in 2017. Negotiations on joining the European Union have been very intensive. All these numerous changes have been turbulent and testify to the transitional position of the country.
} 
Cheating in assessment represents a violation of the rules of AI, by which we understand the expectation of being "honest, trustworthy, responsible, respectful, and fair, by completing work only in ways authorized by... the institution" (Bertram Gallant 2008, pp.10-11). Coursework and examination cheating has almost become common at universities, i.e. it has acquired the status of normative behavior among students (Chapman et al. 2004). Examination cheating has been treated as a more serious type of fraud compared with coursework cheating (Ashworth et al. 1997).

A number of types of fraud have been identified (Jones 2011; Newman 2020), and numerous attempts have been made to classify them (Ashworth et al. 1997; Lothringer 2008). The Glossary for Academic Integrity (Tauginiené et al. 2018) was compiled, and taxonomies contributing to the systematization of the more and more abundant glossary in this field were developed (Lothringer 2008; Tauginiené et al. 2019). Despite researches, taxonomies and numerous activities whose primary purpose is to preserve ethics in higher education, academic fraud is getting more widespread, its types and forms are multiplying, so that it is obvious that classifications and definitions do not considerably contribute to fraud prevention.

\section{Spreading of cheating, its actors and frequency}

We could speak of both individual and collective cheating within the students' community (Lothringer 2008), where collective cheating may be either socially active or socially passive (Thomas 2017). Students' frauds sometimes involve teachers, so that a number of scandals at prestigious universities have been referred to in literature (Aaron and Roche 2013; Robin 2004). Third parties, i.e. persons from outside the academic community, are also getting more and more involved in cheating, so the contract cheating is growing more and more evident (Steel 2017), meaning that ghost writing has become an "industry", as reported by numerous studies (Glendinning 2016; Shahghasemi and Akhavan 2015). The circle of the people involved is getting bigger, while the types of fraud are multiplying, regardless of the only acceptable public (desirably, personal as well) attitude that collecting points and the grade itself must be attained exclusively by hard work and knowledge with due respect to all rules which (un) officially apply to knowledge assessment.

Since the 1990s this topic has been drawing particular attention (Ashworth et al. 1997) and there are numerous studies which have provided valuable insights, but their impact is obviously not enough because the types and forms of academic fraud have been multiplying incredibly fast mostly by means of the Internet and modern technology (Aaron and Roche 2013; Burrus et al. 2013). Besides technology, diversity in the classrooms is another important factor that strongly influences students' cheating (Brodowsky et al. 2019).

Cheating poses a problem around the world (Thomas 2017) and it represents "a threat to the morality of the students, the integrity of their grades, and the reputation of our institutions of higher education" (Aaron and Roche 2013, p.161). The problem of academic dishonesty represents a long-term threat to our entire society. The questionable AI of students, and often of professors (Aaron and Roche 2013; Thomas 2017) is a definite sign that morality of contemporary higher education is not at a satisfactory level. In addition, there is evidence that cheating in education begins long before university (Aaron and Roche 2013), as well as that it continues after university, i.e. at work (Jones 2011; Teixeira and Rocha 2006). If cheating is not prevented in a timely manner, it threatens to reoccur and persist, thus tending to become a common pattern of conduct. 
There are frequent researches of cheating in the disciplines of economy (Brodowsky et al. 2019), medicine (Hrabak et al. 2004), and life sciences (Dömeová and Jindrová 2013), while Joshua Newman (2020) points to a lack of research concerned with studies whose students will work in the public sector. A high degree of self-reporting has been recorded - students admit to having been involved in cheating - but they often do not see it as immoral behavior (Dömeová and Jindrová 2013). Education sciences students also admit to having been involved in cheating (Cummings et al. 2002). Frequent selfreporting is a certain indicator that cheating has acquired the status of habitual behavior.

\section{Factors determining students' cheating}

Both collective and individual factors determine cheating, and cheating has also been associated with certain contexts (Thomas 2017). The cultural context represents the commonest factor which (de) motivates cheating, so that the orientation individualism vs. collectivism has been recognized as that which most influences making ethical decisions (Brodowsky et al. 2019). Cultural individualism directs to an individual who does not subjugate his or her interest to the group, while in collectivism everything is subjugated to the interests of the group (Brodowsky et al. 2019; Thomas 2017). A step further in such researches has been determining such a phenomenon which shows that some cultures and regions in the world more or less tolerate fraud (Brodowsky et al. 2019) through the orientation individualism vs. collectivism. Therefore, societies of the Middle East, North Africa and Eastern Europe have been recognized as utilitarian societies, and "utilitarian cultures are the most tolerant of cheating behavior wherein people view cheating as a way to accomplish the greatest good for the greatest number of people" (Brodowsky et al. 2019, p.26). The authors emphasize an important non-discriminatory idea, i.e. they point out that one should avoid overgeneralizations while determining cultural factors (Brodowsky et al. 2019). In addition to this, much as cultures may have powerful influences, it is clear that they are not the only ones. Certain studies indicate similarities in perception among students coming from radically different cultures (Rawwas et al. 2004). This similarity of attitudes may be explained by communication through social networks.

Directly related to individualism-collectivism is also the relation or construct agencycommunion, where agency represents a tendency by which an individual boosts his or her potentials and forms his or her independence, while communion represents an opposite tendency by which an individual becomes completely devoted to the interests of the collective and directed towards belonging to the collective (Brodowsky et al. 2019; Thomas 2017). In addition to the aforementioned determinants, Thomas (2017) further analyzes several more factors, which have also been recognized as culturally modelled, such as: mind-set (fixed vs. growth mind-set), learning environment (transmission vs. active learning) and motivation. In education it is necessary to encourage growth mindset, active learning approaches (e.g. discussion, problem solving), and students need to be constantly motivated (Thomas 2017).

However, individual certainly are culturally modelled, but they also have some individual characteristics (e.g. demographics, capabilities, attitudes and beliefs) which make them more or less liable to cheating (Ashworth et al. 1997; Brodowsky et al. 2019; Chapman et al. 2004). When they find themselves in a peer group, individuals are especially guided by the culture of that group (McCabe et al. 2001). In student groups peer 
loyalty and fellow feeling are highly valued (Aaron and Roche 2013; Ashworth et al. 1997). Thus a student will rarely report his or her fellow student who is cheating (Aaron and Roche 2013), or they will even express a strong disapproval of the one who reports (Brodowsky et al. 2019).

Student group culture also implies the fact that students often model their behavior according to what they think other students do. Students cheat because they think their peers do that as well (Engler and Landau 2011). Moreover, they find that their fellow students do that more often than they themselves, which is seen "as a justification for their behaviors" (Engler et al. 2008, p.99). Thus Engler and Landau (2011) prove that in fraud prevention it is of particular importance to show students what the behavior of an average student is, i.e. that their perception of fraud is unrealistic (Engler and Landau 2011).

The application of social norms interventions requires consistency, stability and depth, because if there is no consistency in the message on the part of the university, the student will not thoroughly adopt the value (Engler et al. 2008). It is especially important to position learning as a motivating factor for students, because as long as motivation is purely extrinsic (grades), the problem of values is seriously compromised (Aaron and Roche 2013). Students can play a major role in maintaining AI by creating the right climate, but also through peer reporting (Burrus et al. 2013). In addition, institutions are thought to be able to improve AI with appropriate codes of ethics and their being respected (McCabe et al. 2001).

\section{Causes, effects and prevention of fraud}

Various causes of fraud have been identified, such as: pressure (mostly from parents), the desire to increase GPA because of a scholarship and/or getting a job, the fact of being overburdened, a lack of self-confidence, etc. (Davis and Ludvigson 1995). Academic fraud often occurs because of bad time management, "everybody does that", "nobody cares", the material is incomprehensible (Jones 2011). Less personal investment in learning also causes cheating (Colnerud and Rosander 2009). Plagiarism seems to be unclear to students (unintentional plagiarism is also recognized), there is an alienation from the university, the influence of large groups and an emphasis on group studying - students consider these as factors which encourage cheating and plagiarism (Ashworth et al. 1997).

The list of causes is not exhausted, and neither is the list of consequences. It is highly important that students be aware of the consequences of their conduct and understand fully the seriousness of the mistake they make while cheating. When it comes to consequences, it is necessary to point out to students the short-term negative effects (punishments, ignorance of the subject, etc.), but even more the long-term consequences incompetence in the profession and the resulting dangers. Students themselves are unaware of the consequences for those who commit fraud (Aaron and Roche 2013). In that respect students point out that it is of vital importance that faculties take all measures to prevent fraud (Aaron and Roche 2013). In addition to strictly controlling of technical conditions where exams take place, it is particularly important that students be taught responsibility and integrity (Rosile 2007; Trautner and Borland 2013), as well as that they learn to manage their time better (Aaron and Roche 2013). Professors are expected to be more devoted, to create exam tasks in a more creative form (avoiding tasks that can be plagiarized), and to encourage higher forms of learning and thinking 
instead of simply memorizing data (Aaron and Roche 2013; Newman 2020; Thomas 2017). The quality of teaching and assessment must be at a high level (Ashworth et al. 1997).

The authors of the pedagogical orientation assert that the moral education of young people poses a major problem in modern society, so that theories on moral development and learning should be put into function of solving this problem (Caro et al. 2018). Therefore, one of the suggestions is rereading Lawrence Kohlberg's theory with an emphasis on its practical side. According to Kohlberg's theory, it is considerably more important for moral learning to work on the development of students' moral reasoning through moral dilemmas than to teach them attitudes and values in the form of content (Caro et al. 2018). It is precisely the principle of moral reasoning on which Trautner and Borland (2013) suggest the model of teaching by means of the so-called sociological imagination. The model consists of a series of stories encompassing moral dilemmas which are the topic for discussion and analysis (Trautner and Borland 2013). In addition, it is important to keep in mind that certain forms of academic fraud are caused by the fact that it is still necessary to teach some things directly, i.e. in the form of content, because "students may not be as competent at completing academic assignments as educators usually assume that they are" (Newman 2020, p.73). This phenomenon concerns different contents, such as general academic writing, adequate selection of literature and its proper citation, but also other important aspects. Many students do not have learning skills developed (Perović and Vučković 2019).

Anonymous direct question surveys and/or Likert-type scale were the most frequent methods in this research field (Ashworth et al. 1997; Thomas 2017).

\section{Research context}

As for our research context, it is represented by a collectivist culture which is still not oriented enough to growth mind-set, so Thomas's (2017) research corresponds to our context very well, regardless of it having been undertaken on the other part of the planet. Namely, Thomas (2017) study, conducted with 207 university students in Thailand (in an area marked by a collectivist culture), corresponds to our study because Montenegrin culture is also collectivist and belongs to the region of South-Eastern Europe, which is also recognized as an area of collectivist utilitarian cultures (Brodowsky et al. 2019). In addition, teaching and learning at the university level in Montenegro, despite a number of changes that have taken place since the signing of the Bologna declaration in 2003, is still marked by traditional transmissive teaching which does not encourage a growth mind-set and agency, as confirmed by research (Perović and Vučković 2019; Vučković 2010).

The learning environment is mostly marked by traditional transmission teaching, while the motivation for learning is predominantly extrinsic - in the form of points and grades (ETINED Council of Europe Platform on Ethics, Transparency and Integrity in Education, 2018). Students are also often demotivated towards studying because securing employment in a particular field is very hard. It is considered that cheating starts considerably before getting to university.

The Council of Europe ETINED platform published a comparative survey on AI in six South-Eastern European countries, including Montenegro. The greatest disadvantage of that research regarding Montenegro is the fact that a small number of respondents 
participated, especially through the survey (ETINED 2018). However, if we even take this disadvantage into consideration, we still think that the results correspond to the real situation quite well. Among other things, the report indicates:

- the lack of clear guidelines on how to preserve AI at the level of decision makers;

- HEIs do have necessary documentation (codes of ethics), but there are no clear and consistent procedures of their implementation;

- students' cheating is not considered to be a serious problem;

- the respondents indicate that prevention is to be provided by the application of external verification measures (e.g. by software for plagiarism detection and by technical prevention of cheating during exams);

- some students do get training on academic writing, but they find it insufficient (ETINED 2018).

Among other things, the recommendations emphasize the following:

- institutions must improve the learning environment;

- students should be included in the prevention of academic fraud, and it is necessary to encourage them to report fraud;

- academic staff must show responsibility, but also great pedagogical competence (encouraging higher forms of learning, avoiding tasks that can be plagiarized, highly estimating learning, etc.);

- getting familiar with every aspect of AI must be intensified (ETINED 2018).

Interesting information was obtained from students about their treating fraud as a game, and it was noted that some teachers also denied students' cheating, which is drastically different from what students stated (ETINED 2018).

Some of the difficulties Montenegro is facing are: low component values in the Academic Integrity Maturity Model (see Fig. 1); there are examples of unpunished cheating in the media; some students enrol in the university unwillingly, due to the fact that it is hard to get employment; professors do not punish students' cheating (ETINED 2018).

Certain attempts have been made after ETINED's report in order to better treat the problems of AI. Montenegro is the first country in the Western Balkans that adopted The Law on Academic Integrity, in March of 2019. The Law was created within the Project Strengthen Academic Integrity and Combat Corruption in Higher Education, co-funded by the Council of Europe and European Commission (20172019). The whole project was aimed at understanding questions of ethics in higher education and raising awareness about AI. A lot of different activities have taken place within this project in Montenegrin higher education community since 2017, and that means that the questions about AI are put in the centre of academic discussions, both among members of academia (students, teachers, researchers) and members of the wider society. The greatest amount of the debate in Montenegro is about plagiarism and about software checking of plagiarism, but the questions on AI are much wider and deeper and AI consists of the whole set of academic values. 


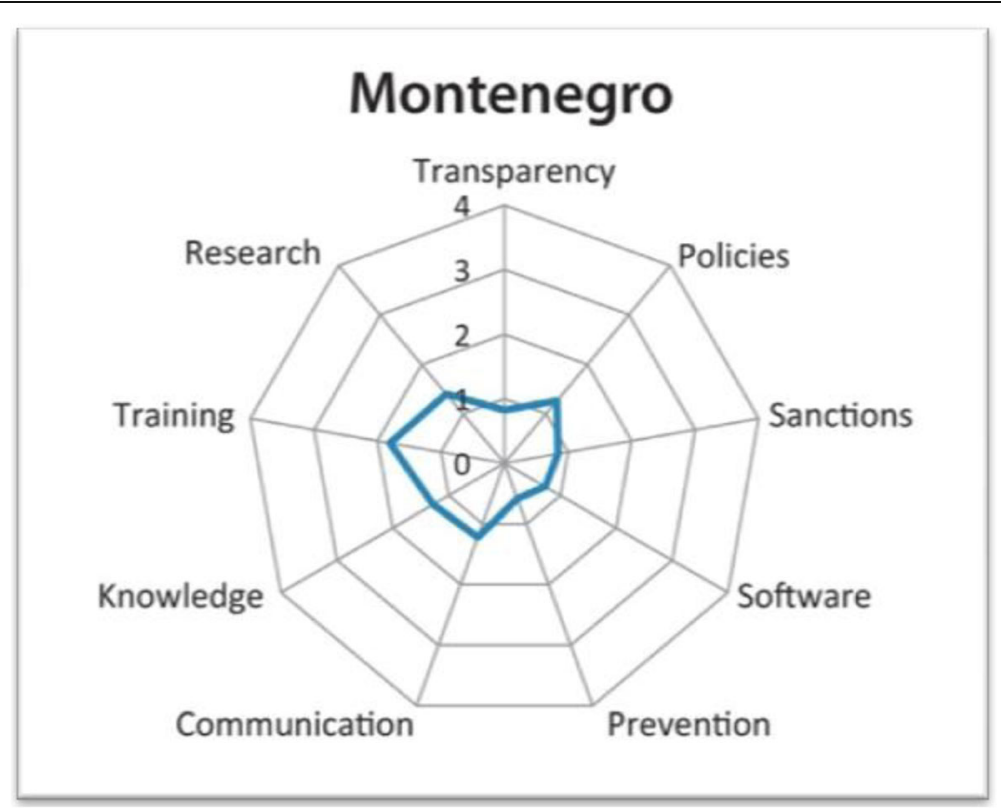

Fig. 1 Academic Integrity Maturity Model radar chart for Montenegro. Source: (ETINED Council of Europe Platform on Ethics, Transparency and Integrity in Education, 2018, p.75)

\section{Methodology}

Research design, aims and objectives

Our aim in this study is to determine students' and teachers' attitudes towards cheating in assessing students' performance. The main research method is case study (Flyvbjerg 2006; Yin 1994). We aim to describe how our respondents:

- Recognize ethical misconduct (EM) in several situations given through case studies,

- Understand the roles of each subject involved,

- Predict consequences of the EM given in the case study and how they understand its possible causes,

- Create individual recommendations to EM or resolve problem situation.

\section{Method}

We used mixed methodology (qualitative and quantitative). Each question that was given to the respondents was open-ended, but it also was possible to code, categorize and thematize the answers (Vilig 2016) and to include quantitative data analysis.

The study design had a roadmap as follows:

a. There are many different types of academic dishonesty in assessing students' performance, so we decided to choose 8 of them from three taxonomies arranged by Lothringer (2008). These taxonomies consider three domains of cheating: exams, writing assignments and other assignments and actions, and they consist of total 66 possibilities of cheating (Lothringer 2008). We chose 8 of them (random choice) and created 8 case studies. These case studies are moral reasoning situations. 
b. Considering the possible "guilty" person in each case study, we decided to have three "guilty" scopes of action: a. guilty student(s), b. guilty teacher(s), c. guilty some other person(s) (other students, persons outside academia etc.). With these three dramatis personae we could have 8 different combinations $\left(2^{3}, 3\right.$ is a number of actors). It is possible to have 8 combinations as we showed in Table 1.

Each case study is created according to one horizontal line and one combination, so we have one situation that is in line with ethical principles by all actors, and also the latest case study shows an example where none of the actors behaved ethically. Considering this, our design gets a better connection with reality.

c. We set up several questions about each case study: Is there any ethical misconduct (EM)? Who (if any) engaged in EM? Why do you think so? Which are the possible consequences of this misconduct? What are the possible causes of this behavior? What would you recommend to be done about this case?

d. We gave our respondents (120 students and 42 teachers) case studies and questions in the written form. Students and teachers responded to the same questions.

Important limitation of this methodology design was the time needed for individual responses (it varied from half an hour to one hour and $50 \mathrm{~min}$, with the arithmetic mean of $46.50 \mathrm{~min}$ ), but our respondents reported that they were highly interested and motivated to understand case studies. They rated the questionnaire's interestingness with a rating of 4.22 on a scale up to five, and the effort invested received an average score of 2.92. So the effort rating is not negligible, but it is very important that the curiosity is valued by a higher score.

The research sample of students (120) includes participants from three basic study programs (pre-school, teacher training and pedagogy), and two postgraduate programs in the field of education. The sample is predominantly female based (114 female and 6 male students), which matches the fact that these studies are almost exclusively "female" studies. The number of students of the first and the second cycle of studies is even (50.1\% master's and 49.9\% bachelor). The sample of teachers was obtained from a number of faculties of the University of Montenegro by random selection - respondents who showed interest in this topic were included. The sample consisted of 28

Table 1 The actors' roles in 8 case studies

\begin{tabular}{|c|c|c|}
\hline \multicolumn{3}{|c|}{ Scope of action } \\
\hline Student & Teacher & Other \\
\hline EB & $E B$ & EB \\
\hline EB & EB & NEB \\
\hline$E B$ & NEB & EB \\
\hline EB & NEB & NEB \\
\hline NEB & EB & EB \\
\hline NEB & $E B$ & NEB \\
\hline NEB & NEB & EB \\
\hline NEB & NEB & NEB \\
\hline
\end{tabular}

$E B$ ethical behavior, $N E B$ non-ethical behavior 
Table 2 Recognizing EM in case studies according to classifications in Table 1

\begin{tabular}{|c|c|c|c|c|c|}
\hline & Respondents & Correct & Partially correct & Incorrect & Total \\
\hline \multirow[t]{6}{*}{ Case study 1} & Teacher & 30 & 1 & 11 & 42 \\
\hline & $\%$ & 71.4 & 2.4 & 26.2 & 100 \\
\hline & Student & 95 & 0 & 23 & 118 \\
\hline & $\%$ & 80.5 & 0 & 19.5 & 100 \\
\hline & Total & 125 & 0 & 34 & 160 \\
\hline & $\%$ & 78.1 & 0 & 21.9 & 100 \\
\hline \multirow[t]{6}{*}{ Case study 2} & Teacher & 35 & 4 & 2 & 41 \\
\hline & $\%$ & 84.4 & 9.8 & 4.9 & 100 \\
\hline & Student & 89 & 22 & 8 & 119 \\
\hline & $\%$ & 74.8 & 18.5 & 6.7 & 100 \\
\hline & Total & 124 & 26 & 10 & 160 \\
\hline & $\%$ & 77.5 & 16.2 & 6.3 & 100 \\
\hline \multirow[t]{6}{*}{ Case study 3} & Teacher & 38 & 0 & 4 & 42 \\
\hline & $\%$ & 90.5 & 0 & 9.5 & 100 \\
\hline & Student & 113 & 0 & 5 & 118 \\
\hline & $\%$ & 95.8 & 0 & 4.2 & 100 \\
\hline & Total & 151 & 0 & 9 & 160 \\
\hline & $\%$ & 94.4 & 0 & 5.7 & 100 \\
\hline \multirow[t]{6}{*}{ Case study 4} & Teacher & 10 & 21 & 11 & 42 \\
\hline & $\%$ & 23.8 & 50.0 & 26.2 & 100 \\
\hline & Student & 31 & 63 & 26 & 120 \\
\hline & $\%$ & 25.8 & 52.5 & 21.7 & 100 \\
\hline & Total & 41 & 84 & 37 & 162 \\
\hline & $\%$ & 25.3 & 51.8 & 22.8 & 100 \\
\hline \multirow{6}{*}{$\begin{array}{l}\text { Case study } 5 \\
p<.05 ; \text { Asymp. Sig. }(2 \text {-sided })=0.011 ; C=0.27\end{array}$} & Teacher & 32 & 0 & 10 & 42 \\
\hline & $\%$ & 76.2 & 0 & 23.8 & 100 \\
\hline & Student & 53 & 1 & 66 & 120 \\
\hline & $\%$ & 44.2 & 0.8 & 55.0 & 100 \\
\hline & Total & 85 & 1 & 76 & 162 \\
\hline & $\%$ & 52.5 & 0.6 & 46.9 & 100 \\
\hline \multirow[t]{6}{*}{ Case study 6} & Teacher & 35 & 7 & 0 & 42 \\
\hline & $\%$ & 83.3 & 16.7 & 0.0 & 100 \\
\hline & Student & 73 & 40 & 7 & 120 \\
\hline & $\%$ & 60.8 & 33.3 & 5.8 & 100 \\
\hline & Total & 108 & 47 & 7 & 162 \\
\hline & $\%$ & 66.7 & 29.0 & 4.3 & 100 \\
\hline \multirow[t]{6}{*}{ Case study 7} & Teacher & 31 & 9 & 2 & 42 \\
\hline & $\%$ & 73.8 & 21.4 & 4.8 & 100 \\
\hline & Student & 86 & 31 & 3 & 120 \\
\hline & $\%$ & 71.7 & 25.8 & 2.5 & 100 \\
\hline & Total & 117 & 40 & 5 & 162 \\
\hline & $\%$ & 72.2 & 24.7 & 3.1 & 100 \\
\hline
\end{tabular}


Table 2 Recognizing EM in case studies according to classifications in Table 1 (Continued)

\begin{tabular}{llllll}
\hline & Respondents & Correct & Partially correct & Incorrect & Total \\
\hline Case study 8 & Teacher & 15 & 27 & 0 & 42 \\
& $\%$ & 35.7 & 64.3 & 0.0 & 100 \\
& Student & 27 & 83 & 9 & 119 \\
$\%$ & 22.7 & 69.7 & 7.6 & 100 \\
& Total & 42 & 110 & 9 & 161 \\
$\%$ & 26.1 & 68.3 & 5.6 & 100 \\
\hline
\end{tabular}

female and 14 male teachers. Mostly younger teachers were included - 38\% had up to 10 years of work in education, and $30 \%$ had from 11 to 20 years of work in education.

Since there is a large imbalance in the overall sample between the number of female and male respondents (142 female or $87.65 \%$ and 20 male or $12.35 \%$ ), we did not analyze the results according to the gender variable. The case studies were balanced in terms of gender, so realistic female and male "characters" appear in them. Considering that female and male "characters" in the case studies were involved in situations with different types and degrees of EM (from copying texts from paper, cheating through bugs, to registering exams without taking them previously), it was not possible to check the respondents' attitude towards the female or male perpetrator of EM. Therefore, the design of this study did not allow us to check whether harsher punishments were intended for male or female "character".

The data we received as answers to questions about causes, effects and recommendations (which we will treat as topics) were processed in accordance with a qualitative analysis, i.e. answers were coded and categorized. We classified 13 codes for effects, 17 codes for causes and 16 codes for recommendations in total. Nine categories were formed in the topics of effects and causes, while 7 were formed in the topic of recommendations. The categories for the three topics are given in Tables 4, 5 and 6.

The accuracy and inaccuracy of the assessment was defined in the following way: if a respondent considered the conduct of all who had participated in the event as (un) ethical, the answer correct was recorded; if he or she considered only certain forms of conduct as such, the answer was partially correct; and if he or she recognized at least one form of conduct as opposite to its real meaning, i.e. if there was a shift between the ethical and the unethical, then the answer was identified as incorrect. The same principle was applied to the respondents' explanations.

\section{Results and discussion}

Our results show good understanding of EM given in the case studies. Each EM was clearly recognized by almost $70 \%$ of the respondents (Table 2). These data confirm that students mostly know what is expected from them (Burrus et al. 2013). Several of the given EM - being incorporated in complex situation in which more than one person was cheating in some way - were not recognized. The only variable which provided us with a few statistically significant differences is the role of the respondent (teacher and student), so that we are delivering the results according to it. Tables 2, 3, 4, 5 and 6 show frequencies and percentages for recognizing EM, explaining EM, suggesting consequences for EM, EM' causes and recommendations for each case study. 
Table 3 Explaining EM in case studies

\begin{tabular}{|c|c|c|c|c|c|}
\hline & Respondents & Correct & Partially correct & Incorrect & Total \\
\hline \multirow[t]{6}{*}{ Case study 1} & Teacher & 31 & 2 & 9 & 42 \\
\hline & $\%$ & 73.8 & 4.8 & 21.4 & $100 \%$ \\
\hline & Student & 98 & 0 & 22 & 120 \\
\hline & $\%$ & 81.7 & 0 & 18.3 & 100 \\
\hline & Total & 129 & 2 & 31 & 162 \\
\hline & $\%$ & 79.6 & 1.2 & 19.1 & 100 \\
\hline \multirow{6}{*}{$\begin{array}{l}\text { Case study } 2 \\
p<.05 ; \text { Asymp. Sig. }(2 \text {-sided })=0.001, C=0.32\end{array}$} & Teacher & 39 & 0 & 3 & 42 \\
\hline & $\%$ & 92.9 & 0 & 7.1 & 100 \\
\hline & Student & 70 & 36 & 13 & 119 \\
\hline & $\%$ & 58.8 & 30.2 & 10.9 & 100 \\
\hline & Total & 109 & 36 & 16 & 161 \\
\hline & $\%$ & 67.7 & 22.4 & 9.9 & 100 \\
\hline \multirow[t]{6}{*}{ Case study 3} & Teacher & 38 & 0 & 4 & 42 \\
\hline & $\%$ & 90.5 & 0 & 9.5 & 100 \\
\hline & Student & 113 & 0 & 5 & 118 \\
\hline & $\%$ & 95.8 & 0 & 4.2 & 100 \\
\hline & Total & 151 & 0 & 9 & 160 \\
\hline & $\%$ & 94.4 & 0 & 5.6 & 100 \\
\hline \multirow[t]{6}{*}{ Case study 4} & Teacher & 12 & 23 & 7 & 42 \\
\hline & $\%$ & 28.6 & 54.8 & 16.7 & 100 \\
\hline & Student & 39 & 72 & 8 & 119 \\
\hline & $\%$ & 32.8 & 60.5 & 6.7 & 100 \\
\hline & Total & 51 & 95 & 15 & 161 \\
\hline & $\%$ & 31.7 & 59.0 & 9.3 & 100 \\
\hline \multirow[t]{6}{*}{ Case study 5} & Teacher & 30 & 0 & 12 & 42 \\
\hline & $\%$ & 71.4 & 0.0 & 28.6 & 100 \\
\hline & Student & 56 & 1 & 62 & 119 \\
\hline & $\%$ & 47.1 & 0.8 & 52.1 & 100 \\
\hline & Total & 86 & 1 & 74 & 161 \\
\hline & $\%$ & 53.4 & 0.6 & 46.0 & 100 \\
\hline \multirow{6}{*}{$\begin{array}{l}\text { Case study } 6 \\
p<.05 ; \text { Asymp. Sig. }(2 \text {-sided })=0.035, C=0.25\end{array}$} & Teacher & 35 & 7 & 0 & 42 \\
\hline & $\%$ & 83.3 & 16.7 & 0.0 & 100 \\
\hline & Student & 69 & 38 & 9 & 116 \\
\hline & $\%$ & 59.5 & 32.8 & 7.8 & 100 \\
\hline & Total & 104 & 45 & 9 & 158 \\
\hline & $\%$ & 65.8 & 28.5 & 5.7 & 100 \\
\hline \multirow[t]{6}{*}{ Case study 7} & Teacher & 32 & 8 & 2 & 42 \\
\hline & $\%$ & 76.2 & 19.0 & 4.8 & 100 \\
\hline & Student & 69 & 31 & 20 & 120 \\
\hline & $\%$ & 57.5 & 25.8 & 16.7 & 100 \\
\hline & Total & 101 & 39 & 22 & 162 \\
\hline & $\%$ & 62.3 & 24.1 & 13.6 & 100 \\
\hline \multirow[t]{2}{*}{ Case study 8} & Teacher & 17 & 25 & 0 & 42 \\
\hline & $\%$ & 40.5 & 59.5 & 0.0 & 100 \\
\hline
\end{tabular}


Table 3 Explaining EM in case studies (Continued)

\begin{tabular}{llllll}
\hline Respondents & Correct & Partially correct & Incorrect & Total \\
\hline Student & 28 & 81 & 9 & 118 \\
$\%$ & 23.7 & 68.6 & 7.6 & 100 \\
Total & 45 & 106 & 9 & 160 \\
$\%$ & 28.1 & 66.2 & 5.6 & 100 \\
\hline
\end{tabular}

We have used Spearman's rank correlation coefficient to evaluate the registered effects, causes and recommendations. In three cases we have obtained high coefficient values. In case study 6 , in the teachers' sample it has been noted that a better knowledge of the consequences reduces the cause $\left(\mathrm{r}_{\mathrm{S}}=-0,849 ; p=0,016\right)$. In case study 3 , in the students' sample a better knowledge of the causes leads to better recommendations $\left(r_{S}=0,841 ; p=0,036\right)$. In the same sample for case study 8 , a better knowledge of the causes leads to a better understanding of the consequences $\left(\mathrm{r}_{\mathrm{S}}=0,964 ; p<0,001\right)$.

We are presenting the results in accordance with particular stories, whereas we have to point out that most categories which were recognized for a single story in terms of causes, effects and recommendations are practically the same for all case studies. However, differences occur in terms of the frequency of certain categories from one story to another. We are presenting case studies according to the order from Table 1.

\section{Case study 1}

The results of case study 1 that was ethically clear are very interesting. In this case study the student was able to see exam questions which happened to be near him, because the professor left her office for some time and students were left alone there. However, it is clear from the case study that the student was uncertain ("many question went through his mind"), but he resisted the temptation. As in every case study, there was an ethical dilemma with this one, but it was resolved in the correct way. Almost 30\% of teacher respondents described the situation as EM, while the same reasoning came from more than $20 \%$ of students (Table 2). The respondents who identified EM pointed to the professor's recklessness in their open comments (14\%), and they also showed distrust of the student - 19\% of the respondents were convinced that the student had actually seen the questions, as well as that he had kept them to himself (there were a few more students in the professor's office). The respondents' explanations given in the form of open answers confirmed their estimation (Table 3).

Such answers confirm the presence of distrust in academia as well as the assumption that students most certainly cheat if given a chance. The same respondents state that the student was selfish ("he did not tell his fellow students"), curious ("he took a look at the professor's desk"), and they recommend that "he should not look at other people's stuff". Even though it is clearly stated in the case study that the student accidentally spotted the questions on the pile of papers on the desk, these answers indicate that strict prohibitions and forms of control are required, which was confirmed by the answers which followed. Therefore, in our respondents' opinion, the locus of control is predominantly external, which indicates the need for a number of changes in 


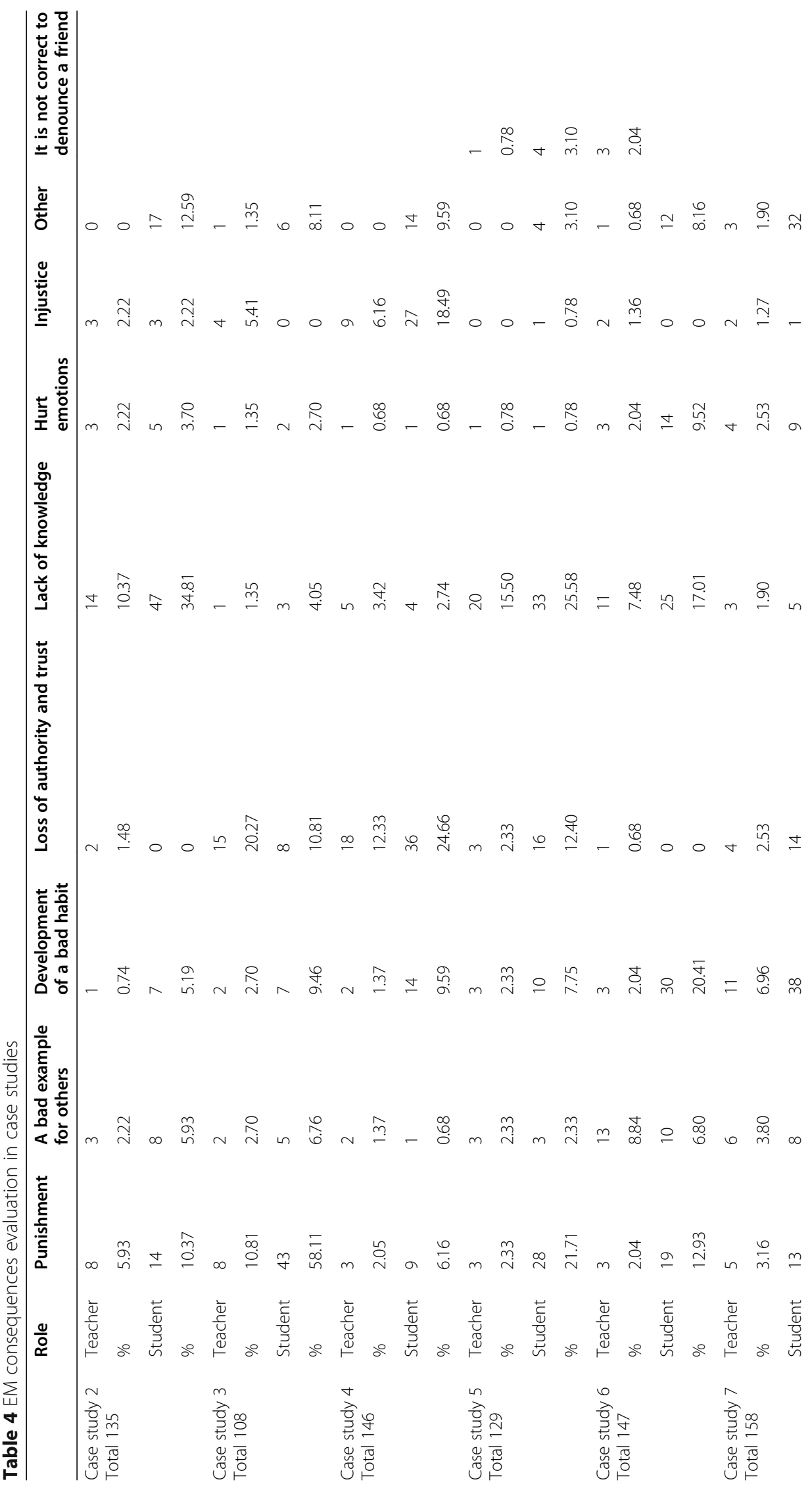




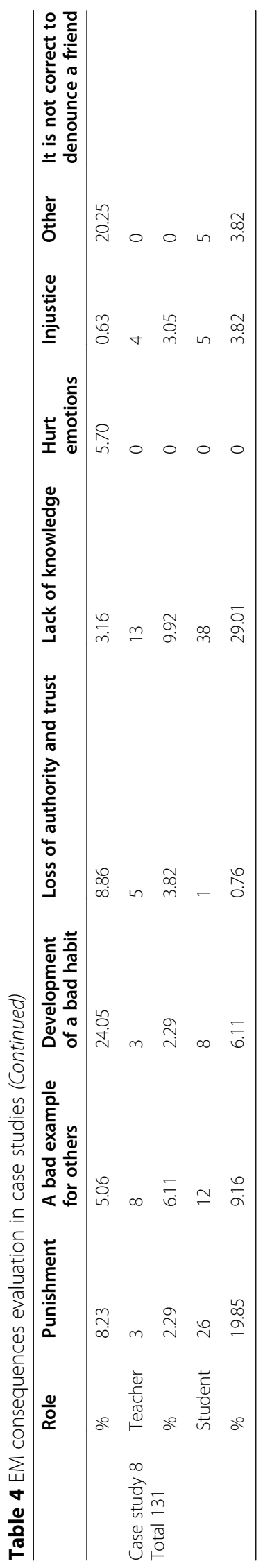




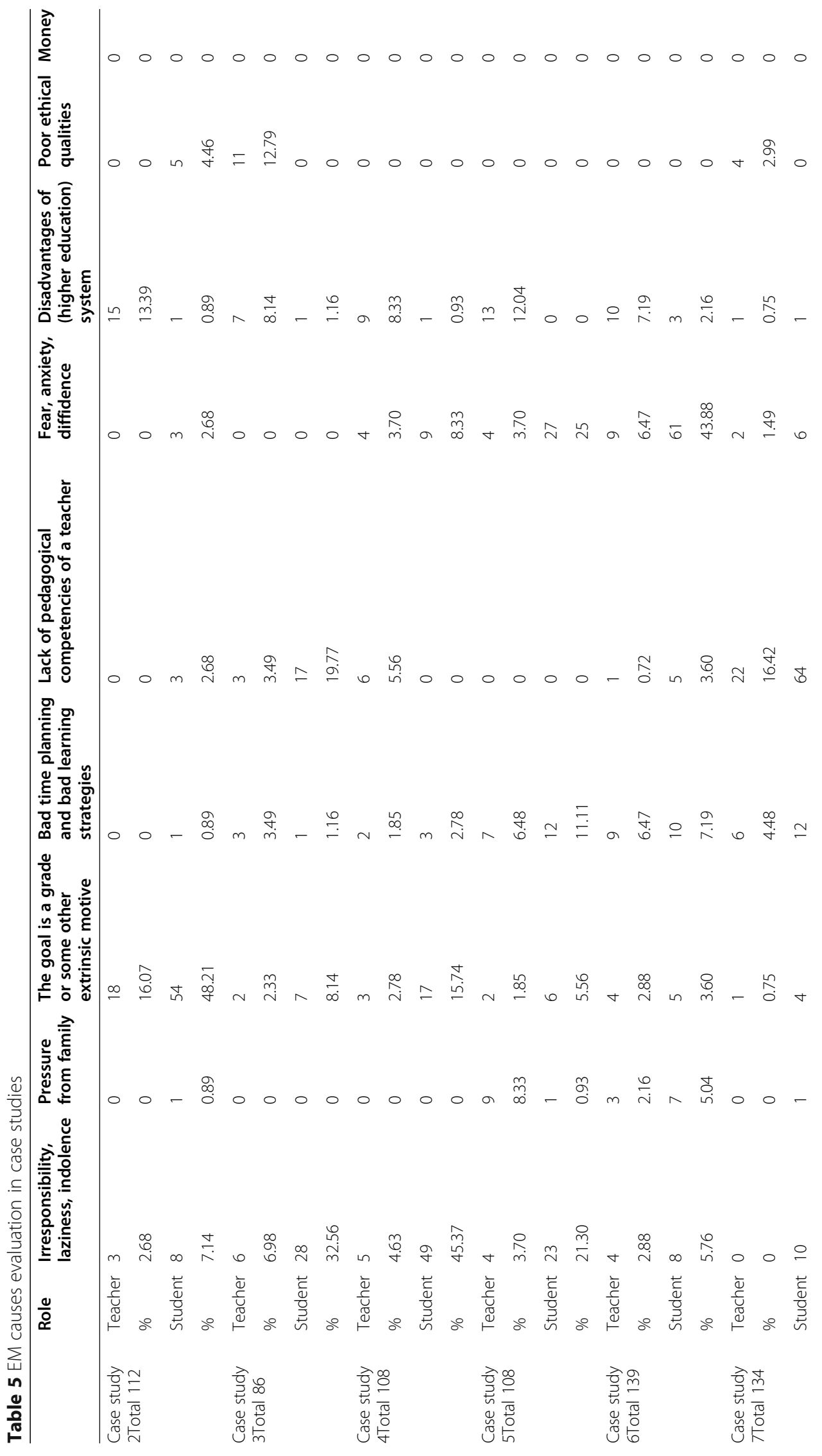




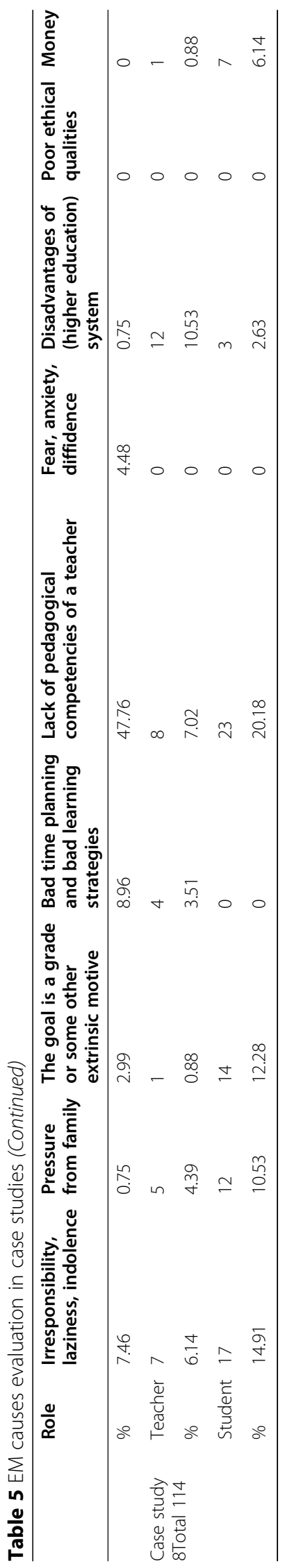




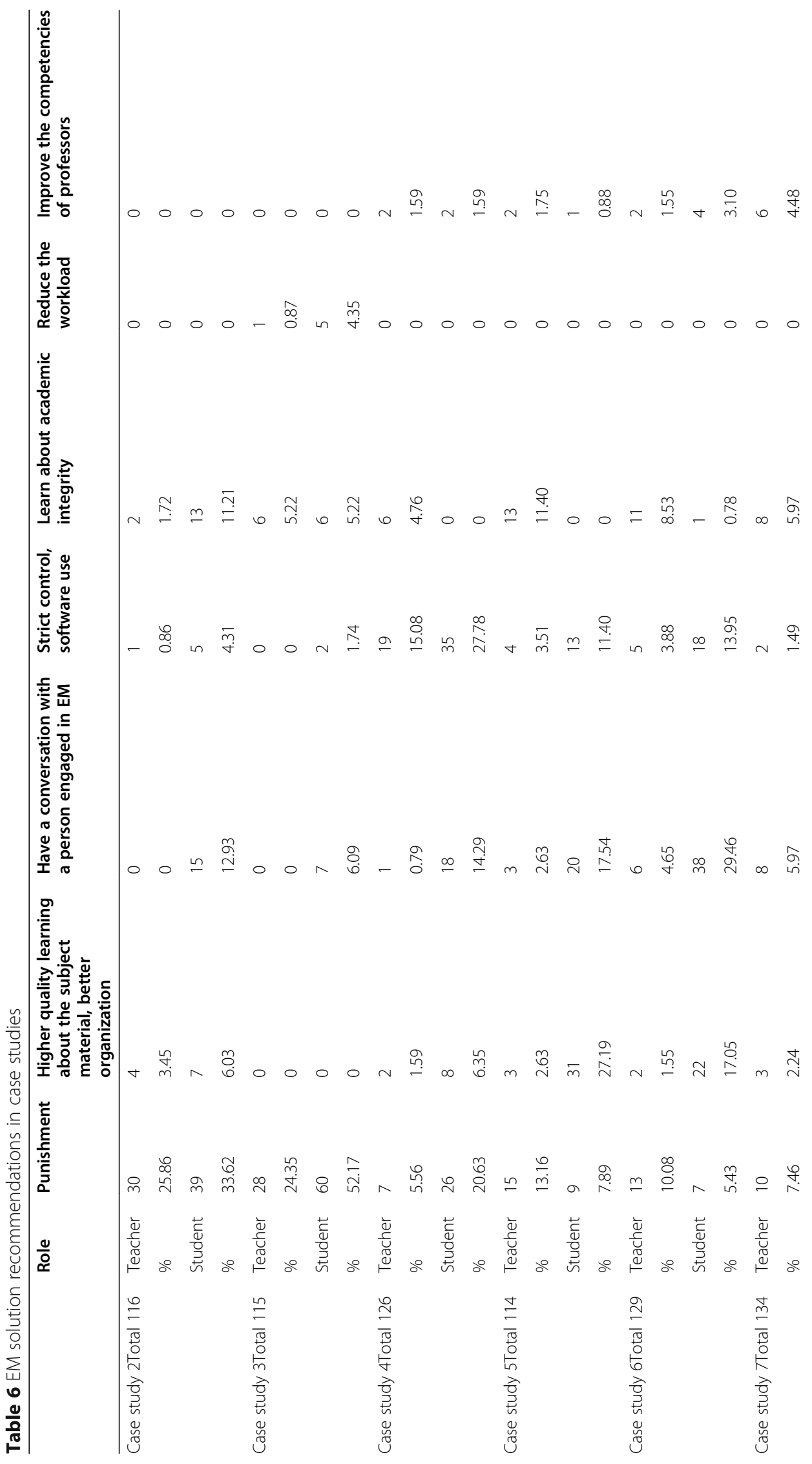




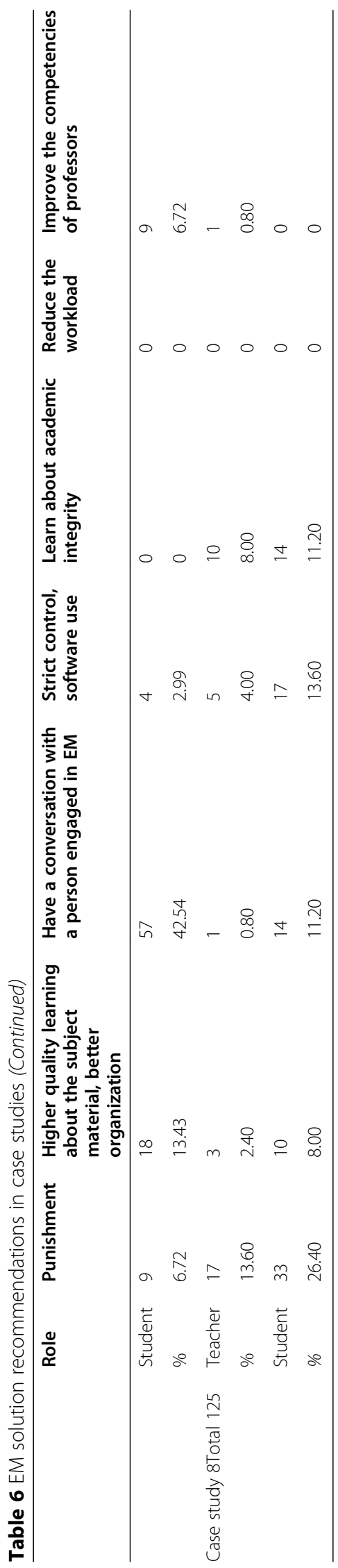


education. Namely, only when students have developed self-control, is it then possible to speak about interiorized ethical norms.

Other respondents from the teacher group (71\%) and the student group (80\%) did not observe EM (Table 2). Their comments confirmed this - they point out that the student resisted the temptation and wrote comments such as: "May he keep it up!" This group states that the professor was not careless, only that she trusted the students, and trust relationships are what should be built in higher education.

As for the three topics where open comments were asked (effects of conduct, causes and recommendations), few categories were classified. In this case study these are the categories which originate from the group of wrong estimations of EM, so in terms of effects the respondents think that the professor is in danger of losing her authority, because she failed to exercise strict control (4 respondents), and she allowed injustice to occur (3 respondents). The professor's insufficient pedagogical competencies were stated as the causes of EM ( 5 respondents), as well as the student's fear of the exam (5 respondents). Among the recommendations we have noted the need for: strict control (11 teachers and 4 students), learning about AI (5 teachers) and the student's punishment (2 students). All open comments came from the respondents who had recognized EM in an ethically correct dilemma.

\section{Case study 2}

The second case study deals with a student of medicine who cannot pass his anatomy exam, even though he has studied hard. His ambitious mother bribes a person from the faculty administration (her schoolmate), and she records a positive grade. The student does not know what his mother has done. This case study provoked intense and extensive reactions from the respondents. In all likelihood, the studies of medicine must be in particular ethically pure, since they are directly associated with health care.

The way in which our respondents recognized EM in the case study is given in Table 2 , whereas the accuracy of their explanations is stated in Table 3. The answers which are marked as incorrect labelled the student as the perpetrator of EM, while the partially correct answers excluded the mother, probably guided by the logic that she was not a member of the academic community. However, in the introductory part of the questionnaire it was not stated that the case studies related exclusively to members of the academic community.

The explanations of students and teachers differ considerably in statistical terms (Table 3). The students failed to recognize some of the perpetrators of EM and a number of them identified the student from this case study as a responsible one.

The respondents expressed the most reactions for this case study, especially in the part concerning the effects (Table 4) of EM ("He will be a lousy doctor", "He'll kill somebody", "Everybody is guilty - the student, his mother, the administration clerk, the professor who does not exercise control"). The number of comments and the intensity of reactions of the respondents point to their opinion that the medical profession is such that people's lives depend directly on it, so it goes without saying that it needs to be free from all types of EM. 
The causes which had led to EM were mostly recognized as part of extrinsic motivation for conduct in academia (the grade is the aim, not learning and knowledge), even though we recorded different reactions as well (Table 5). The teachers (15 of them) indicated that this case confirmed the disadvantages of the system of studying.

A third of our sample advocates harsh punishments for all participants (Table 6), but there are such respondents who feel it is sufficient to interrogate the student and others involved in the situation. More responses from the respondents who emphasize the necessity of learning about AI are also recorded here. The responsibility of the institution is particularly emphasized in relation to the administration clerk (Table 6), who is urgently to be "most severely punished, fired and prosecuted". The respondents mostly seek the most serious punishment for the student's mother (prosecution), while they identify the student as a victim of his mother's ambition. However, he is not completely absolved in their opinion (one respondent wrote "the student should denounce his mother") and is expected to acknowledge everything to the faculty services and ask for a retake, having realized that he got a grade for the exam he did not pass. The comments also highlight the possible poor learning strategies.

\section{Case study 3}

In this case study a student finds out that her former mentor has published a book in which he included her diploma paper, among other students' papers. The professor published the book under his own name exclusively. This case study opens a dilemma among students whose works have been plagiarized which makes them emotionally hurt and disappointed. They are uncertain whether to denounce the professor or not.

Apart from several ( 9 in total) answers which indicate that a teacher "is entitled to students' works, because the mentor is a co-author", other respondents clearly state that the professor expressed EM (Table 2). Their explanations confirm this (Table 3). Almost all of them explicitly identified the professor's conduct as plagiarism or intellectual theft.

The respondents are almost unanimous about this case of plagiarism - the professor should be denounced and he has to bear consequences for such behavior (Table 4). Among other things, one of the respondents states: "The book should be declared an act of plagiarism, while all professor's works should undergo verification. If this was not the single instance of plagiarism, he would be fired." This comment and the similar ones show that some students are very well acquainted with the regulations of AI, which can be explained by a significant number of activities related to AI having been realized since 2017. In this case study the respondents (23 of them) point out that the professor is in danger of losing his authority and reputation, which in our respondents' estimation represents a highly serious consequence of his unethical conduct. The reputation of university professors is something which is still highly appreciated, even though a gradual change of attitude has been noted especially due to several scandals which have shocked the public. A few comments which also appear here focus on the hurt emotions of those students whose works were appropriated by the professor.

As for the causes which had led the mentor to the EM situation, the respondents identify the absence of hard work and the lack of teaching competencies by frequency, followed by "the bad character" (Table 5). The respondents convincingly recommend 
very harsh punishments for the professor, from declaring the book a piece of plagiarism to taking away both the academic rank and the job from the professor (Table 6).

\section{Case study 4}

A student who is good at statistics sends a completed piece of homework to a fellow student. The latter submits the homework as his own, after which the real author of the homework also submits the paper. The professor notices two identical pieces of homework and invites the student who was the first to submit the homework for an interview. Since he does not manage to find out the truth, the professor decides not to deal with it any longer allocating no points to either of them.

We obtained extremely interesting views on EM (Table 2) and their explanations (Table 3). The respondents disapproved of the student's behavior and they treated his act as uncongenial. Interestingly enough, in this case study we also obtained the comments which indicated that the behavior of the student who had sent the homework to his friend was unethical - he shouldn't have sent the homework to a fellow student. A considerable number of the respondents did not recognize the professor's EM, i.e. they did not treat his decision "not to deal with it any longer" as an unprofessional attitude. The given explanations, however, described the EM somewhat better and more meticulously (Table 3).

As for this case, a lot was said about emotions, which was explained by the respondents in terms of peer loyalty being disrupted. They emphasized that the student was hurt, that he had lost his trust in his "friend" (student who copied his answers), so that he would no longer trust anyone (Table 4). The respondents thought that the professor "had to solve the situation", because in this was he let the students themselves solve the problem which objectively related to the very course and the professor as well. Many comments indicated that the students needed to give a precise description of the situation so that the problem could be justly solved. Concerning this case study, the loss of amiable relations was particularly emphasized, followed by the unjust gaining of points as a result of the action of the student who had submitted someone else's paper under his own name (Table 4).

Among the causes of EM the student's indolence and irresponsibility (Table 5) are particularly emphasized as well as his extrinsic motivation (points and grades). What follows is a recognition of the student's fear or anxiety, which was not discussed in the case study. Very few respondents (only 6 teachers) point out that the professor lacks the competencies to resolve the situation in an ethically acceptable manner.

The respondents recommend rigorous scrutiny, penalties, interviews with the participants (Table 6), and a smaller number of them address essential pedagogical issues, such as: the need for quality learning, better teacher competencies, and the lack of knowledge and skills related to AI.

\section{Case study 5}

A student is cheating (copying the answers) during the exam and rustling the papers from which she is copying she is making noises which disturb her fellow students. Another student, visibly irritated, tells her aloud to stop doing that because she is disturbing others. She mentions that her fellow student is a "copycat" who does that all the time. The professor was at the other end of the amphitheatre and noticed nothing. This case study refers to mass studies of economics, so it is realistic that 100 or more 
students take the test in the same amphitheatre. In such numerous groups, it is possible that the professor does not notice two distant students arguing out loud without shouting. Additionally, the emphasis of this case study was on the relationships between students in a situation involving EM, as well as on their reactions to cheating. Therefore, the professor is deliberately "removed" to the other end of the amphitheatre so that students can first try to confront EM on their own. Since the person who is cheating has not stopped, the other student reports her to the professor who takes away her paper without much discussion and orders her to leave the examination room.

In this case study, the students primarily noticed the girl who reported the act of cheating (more than 41\%) (Table 2). In addition, statistically significant differences were identified as well as a very high contingency coefficient $(C=0.27)$. Such answers from our respondents indicate that denouncing somebody who has committed EM is not at all desirable in Montenegrin culture, even if that person visibly prevents you from finishing your work. The explanations given mostly focus on the girl who reported the cheating and only after that they focus on the person who committed EM (Table 3).

The reactions already reported by other studies emerged among the students - they express a (very) strong tendency towards peer loyalty (Aaron and Roche 2013; Ashworth et al. 1997), so peer reporting is strongly rejected (Table 3). Furthermore, since they belong to a collectivist culture, the students among our respondents label the student who reported cheating as "a snitch", "a traitor", i.e. they use derogatory words. Some go even further in their comments stating that the student reported "because she is jealous" (This explanation remained unclear, because the case study did not point out any reason why anyone would be jealous of the girl who is copying.), "obnoxious", "telltale", "doesn't mind her own business", etc.

The students identified the following key effects of EM: the lack of knowledge, the fact that the student's cheating was discovered (which is identified as a punishment), as well as the loss of trust among fellow students (Table 4). The professors are also oriented towards the lack of knowledge as a serious consequence.

As in most case studies, some of the respondents point to the student's irresponsibility and indolence as the primary causes (Table 5), then to anxiety which students experience during written examination, then to bad learning habits, but also to the disadvantages of the system of higher education (this group contains exclusively the professors' answers).

In order to avoid such situations, the respondents consider that it is necessary to study harder, and to talk to the student and to clearly indicate to her the seriousness of the mistake she is making while taking her exams in this way (Table 6). In addition, some respondents express the need for stricter control of the process of examination and they think that professors should provide the questions "which cannot be copied from the secretly prepared lists". The professors (13 of them) believe that this case study also indicates the need for learning about AI.

\section{Case study 6}

A student is anxious during the exam, and even though she has studied the best she could she is now taking the exam using "bugs". Another student from her group is dictating the answers. She manages to pass the exam. 
This case study was in general correctly perceived in ethical terms, even though a considerable number of students failed to notice the unethical behavior of the student who dictated the answers (Table 2). A smaller group of teachers produced similar answers. The situation was even more polarized in the explanations of the two groups of respondents, so that statistically significant differences appeared (Table 3). These differences indicate that the students find the EM of the student who dictated the completed questions less obvious.

The most frequent among the effects (Table 4) include the development of a bad habit, a lack of knowledge, a bad example for other students, a possible punishment ("if somebody happens to speak out - too many are involved in the act of fraud"), as well as hurt feelings of those students who passed their exam in a regular way.

The case study explicitly states that the student was anxious, which represents the primary cause in our respondents' opinion (Table 5), while they also identify some other, such as: underdeveloped learning habits, the flaws of the system of higher education, indolence, as well as the pressure coming from the family and a grade as motivation. This case study obviously inspired identification among the students, because they expressed a great amount of understanding for the phenomenon of anxiety. Here they also suggest the issue of communication with professors, which is a frequent cause for anxiety in their opinion.

What dominates among the recommendations (Table 6) is an interview with the perpetrators of EM, then a strict control during examination, as well as the need to study harder, i.e. in a more organized and quality manner.

\section{Case study 7}

A student has forgotten about the deadline of submitting the seminar paper. He asks the professor to extend the term, but the latter rejects, insulting the student as well as his fellow students who are supporting him. Pressured to meet deadlines, the student submits a plagiarized paper.

More than $70 \%$ of the respondents recognized EM (Table 2), while fewer were accurate in their explanations (Table 3). This study inspired the respondents to comment on the fact that students are sometimes overburdened while studying as well as on the real situation in which "one deadline immediately follows another or they even coincide". It is interesting that some respondents consider the professor's attitude to be unethical, because he did not alter the term. Partially incorrect interpretation of ethical norms has been noticed in such comments. The professor did not engage in EM not having altered the term for paper submission (in Montenegrin higher education system there is a frequent notion that somebody "does (not) come to students' assistance", which implies extremely diverse forms of behavior on the part of professors who meet students' requests with or without reason), but he expressed it insulting the students - which was correctly identified by most respondents.

The development of a bad habit of the student, a possible punishment, a bad example for others, as well as the professor's loss of authority and the students' hurt feelings are the most frequent effect of the discussed EM (Table 4). As for the cause, a lack of pedagogical skills of the professor is dominantly emphasized (Table 5). A conversation is the preferred solution, rather than punishment, and the respondents justify this by the fact that the student's act was a direct consequence of the professor's irresponsible behavior (Table 6). 


\section{Case study 8}

A student hires a person (a ghost-writer) who "writes" for her a diploma paper. A ghost-writer plagiarized a diploma paper because the student said that she was in a hurry to graduate. The professor recognizes plagiarism, but allows the student to defend the thesis, because "a job is waiting for her".

A small number of respondents fully recognized EM (Table 2), and their explanations were similarly successful as well (Table 3). The ghost-writer, as a person outside academia, was not identified as a perpetrator of EM, except in terms of "not having done the job for which he/she had been paid properly". The ghost writer was accused by this comment of direct and unskilled plagiarism, which indicates a serious lack of AI in the student who commented. High solidarity among the responding students was obtained related to this case study. They frequently justified the actions of the characters, explaining that the student's "life is at stake".

As for the effects, they are as follows: a lack of knowledge, a possible punishment (a number of persons were involved in EM here as well), and a bad example for others (Table 4). Concerning the causes (Table 5), our respondents noticed a lack of teaching competencies ("the professor had an opportunity not to allow the defence of such thesis"), the student's and the professor's irresponsibility and indolence, and extrinsic motivation (obtaining a diploma at all costs).

The most common recommendations (Table 6) suggest punishment, the need to learn about AI, strict control and the use of software for the purpose of authentication.

\section{Recommendations}

A great number of our respondents advocate punishments for those who commit EM in assessing students' performance. Institutions are definitely obliged to have developed procedures for combating every form of EM, meaning procedures that will be clear and familiar to all members of the academic community in advance. Text-matching software is also an important tool. However, from a pedagogical point of view, it is crucially important to learn about academic integrity, which fundamentally implies notions on academic writing, the use of literature, moral reasoning, and an ethical attitude towards teaching and learning. The respondents have also drawn attention to the fact that the lack of learning skills represents a common cause of EM; therefore, they need to be given particular attention. Teachers' competencies have to be improved as well - a number of respondents have stated in their open comments that "all these situations occur in reality", which suggests the need that teachers should also be more familiar with the rules of AI, it is important that they be more competent while designing tests (so that they cannot be directly plagiarized) and that they be more responsible while invigilating and grading written papers.

When it comes to the recommendations for future research, this topic is only becoming dominant in Montenegro; so many basic data are still missing. Every segment of academic integrity is to be well known, while it is highly important that the results of research have practical implications, i.e. a direct impact on university policies regarding AI.

\section{Conclusion}

Our respondents have recognized most forms of EM well enough, although in some situations, the respondents perceived other errors (poor organization of time for learning, 
professors' strict deadline for paper submission, etc.) as EM. Certain manifestations of EM have not been recognized, which may possibly be a consequence of complex situations. For instance, the professor in case study 7 had two activities: 1 . he refused to alter the term for the submission of papers, and 2. he insulted the students. Some respondents have identified his first action as EM, while they have failed to pay attention to his second action. Therefore, the issues of ethics are not completely clear to all respondents, which leads to the conclusion that universities must organize trainings in this field.

Both groups of respondents understand EM in a similar way, and whether it is a professor or a student (or students) who commits EM has not affected their responses. We have not found consistent statistically significant differences between them when considering identification of EM and a guilty person in a given situation. Interestingly enough, both groups have emphasized the importance of peer loyalty (case study 5), which is probably a consequence of firm social patterns. This also indicates the fact that in the present circumstances it is hardly expected that students will publicly criticize the one who is cheating in Montenegrin higher education system. However, we think that it is necessary to work with them on the prevention of fraud by discussing the consequences (especially the longterm ones, which were not considerably discussed in the comments), by learning ethical reasoning, and by developing functional strategies of learning for the purpose of preventing fraud. In addition, both groups of respondents have expressed the most intense reactions and given the most extensive responses to the case study dealing with the student of medicine. Furthermore, both groups have expressed weaker reactions to the unethical conduct of persons who are not members of the academic community (for example, the ghostwriter in case study 8). This at least partly indicates an understanding that the responsibility for academic conduct must solely rest on members of the academic community.

Some older students (masters' level and senior years of study) evaluate EM more rigorously - they anticipate more severe consequences and more frequently seek for causes in individual responsibility, but a few comments recorded have not resulted in statistically significant differences in relation to younger students. Younger students look for causes in overwork (which they associate with the lack of learning skills and/or bad time planning), as well as in poor competencies of professors. The professors sometimes believe that students are lazy, and that they "learned how to cheat, even before coming to university."

Within the third research objective (predicting consequences and understanding possible causes) we have found some differences which we could describe as colored by personal role. Namely, when the students are describing consequences of EM that was committed by students within the case study, they are slightly permissive while for teachers they tend to be stricter. The teachers respondents are strict in both situations, and their commonest recommendation is punishment or strict control. The students also frequently mention punishment, yet a bit lower in percentage terms. This group has frequently recommended the conversation with the perpetrator of EM. It is expected that punishment and strict control will represent a way of preventing EM, but we think it is equally important, if not more important, to raise awareness of non-ethics and its consequences for an individual and for society, as well as to learn about AI as a teaching goal, and to develop the manner of thinking which is ethical (i.e. learn ethical reasoning). When considering the causes, the students tend to be more diverse in their ideas (all 17 codes were registered in their group), while the teachers' group is more homogenous (9 codes). 
Taking into consideration that our respondents showed great interest in participating in a study that had a rather complicated structure composed of eight case studies, we believe that students and teachers from our sample are ready and motivated to seriously confront the problems produced by EM. Many of our respondents' reactions lead to the conclusion that the academic community, or at least part of it, perceives the serious threats emerging as a result of EM. Identifying the problem is the first step towards solving it, so we believe that this first step in the field of AI has been made.

\section{Abbreviations}

EM: Ethical misconduct; ETINED: The Council of Europe Platform on Ethics, Transparency and Integrity in Education; Al: Academic integrity; GPA: Grade Point Average

\section{Acknowledgements}

This manuscript has been produced in the framework of the national project 01-792 entitled "Strengthening Academic Integrity - Interdisciplinary Research-based Approach to Ethical Behavior in Higher Education" which was financed by the Ministry of Science of Montenegro.

\section{Originality and review status}

The authors confirm that this work is original and has not been published elsewhere, nor is it currently under consideration for publication elsewhere.

\section{Authors' contributions}

This article was written by the lead author with support from the second, third and fourth author who helped in data collection, data processing, and disscusion. The percentage of contributions is indicated by the order of authorship provided. The author(s) read and approved the final manuscript.

Funding

Financed by the Ministry of Science of Montenegro.

\section{Availability of data and materials}

The original research data upon which the Tables in this article are based is held by the Lead Author. The data is available on the request. The data is in local language(s).

\section{Competing interests}

The authors declare that they have no competing interests.

\section{Author details}

${ }^{1}$ Faculty of Philosophy, University of Montenegro, Cetinjski put bb, Podgorica, Montenegro. ${ }^{2}$ Faculty of Tourism and Hotel Management, University of Montenegro, Cetinjski put bb, Podgorica, Montenegro. ${ }^{3}$ Faculty of Law, University of Montenegro, Cetinjski put bb, Podgorica, Montenegro.

Received: 12 August 2020 Accepted: 9 November 2020

Published online: 27 November 2020

\section{References}

Aaron LS, Roche C (2013) Stemming the tide of academic dishonesty in higher education: it takes a village. J Educ Technol Syst 42:161-196. https://doi.org/10.2190/FET.42.2.h

Ashworth P, Bannister P, Thorne P (1997) Guilty in whose eyes? University students' perceptions of cheating and plagiarism in academic work and assessment. Stud High Educ 22:187-203. https://doi.org/10.1080/03075079712331381034

Bertram Gallant T (2008) Academic integrity in the twenty-first century: a teaching-learning imperative. Jossey-Bass, San Francisco

Brodowsky GH, Tarr E, Ho FN, Sciglimpaglia D (2019) Tolerance for cheating from the classroom to the boardroom: a study of underlying personal and cultural drivers. J Marketing Educ 42:23-36. https://doi.org/10.1177/0273475319878810

Burrus RT, Jones AT, Sackley B, Walker M (2013) It's the students, stupid: how perceptions of student reporting impact cheating. Am Econ 58:51-59. https://doi.org/10.1177/056943451305800106

Caro S, Ahedo Ruiz JC, Esteban Bara F (2018) Kohlberg's moral education proposal and its legacy at university: present and future. Revista Española de Pedagogía 76:85-100. https://doi.org/10.22550/REP76-1-2018-12

Chapman K, Davis R, Toy D, Wright L (2004) Academic integrity in the business school environment: I'll get by with a little help from my friends. J Marketing Educ 26:236-249 Accessed 12 Jan 2020 from https://www.learntechlib.org/p/64906/

Colnerud G, Rosander M (2009) Academic dishonesty, ethical norms and learning. Assess Eval High Edu 34:505-517. https:// doi.org/10.1080/02602930802155263

Cummings R, Maddux CD, Harlow S, Dyas L (2002) Academic misconduct in undergraduate teacher education students and its relationship to their principled moral reasoning. J Instr Psychol 29:286-296. https://doi.org/10.12691/education-2-11-9

Davis SF, Ludvigson HW (1995) Additional data on academic dishonesty and a proposal for remediation. Teach Psychol 22: 119-121. https://doi.org/10.1207/s15328023top2202_6

Dömeová L, Jindrová A (2013) Unethical behavior of the students of the Czech University of life sciences. Int Educ Stud 6:7785. https://doi.org/10.5539/ies.v6n11p77 
Engler JN, Landau JD (2011) Source is important when developing a social norms campaign to combat academic dishonesty. Teach Psychol 38:46-48. https://doi.org/10.1177/0098628310390848

Engler JN, Landau JD, Epstein M (2008) Keeping up with the joneses: students' perceptions of academically dishonest behavior. Teach Psychol 35:99-102. https://doi.org/10.1080/00986280801978418

ETINED Council of Europe Platform on Ethics, Transparency and Integrity in Education (2018) South-east European project on policies for academic integrity - Vol 5, Council of Europe, Strasbourg

Flyvbjerg B (2006) Five misunderstandings about case-study research. Qual Inq 12:219-245. https://doi.org/10.1177/ 1077800405284363

Glendinning I (2016) European perspectives of academic integrity. In: Bretag T (ed) Handbook of academic integrity. Science+ Business Media Springer, Singapore, pp 55-74

Hrabak M, Vujaklija A, Vodopivec I, Hren D, Marušić M, Marušić A (2004) Academic misconduct among medical students in a post-communist country. Med Educ 38:276-285. https://doi.org/10.1111/j.1365-2923.2004.01766.x

Jones DR (2011) Academic dishonesty: are more students cheating? Bus Commun Q 74:141-150. https://doi.org/10.1177/ 1080569911404059

Lothringer LB (2008) Evaluation of the use of an academic integrity training course as a proactive measure encouraging academic honesty. Doctoral dissertation 15714. lowa State University. https://doi.org/10.31274/rtd-180813-7895

McCabe DL, Trevino LK, Butterfield KD (2001) Cheating in academic institutions: a decade of research. Ethics Behav 13:219232. https://doi.org/10.1207/S15327019EB1103_2

Newman J (2020) Academic integrity in public administration programmes: practical reflections on prevention and response. Teaching Public Administration 38:63-77. https://doi.org/10.1177/0144739419864128

Perović $\boxminus$, Vučković $D$ (2019) Success in studying at the University of Montenegro: is there hyper-production of diplomas? Interdiscip Descr Complex Syst 17:385-402. https://doi.org/10.7906/indecs.17.2.13

Rawwas MYA, Al-Khatib JA, Vitell SJ (2004) Academic dishonesty: a cross-cultural comparison of U.S. and Chinese marketing students. J Marketing Educ 26:89-100. https://doi.org/10.1177/0273475303262354

Robin RT (2004) Scandals and scoundrels: seven cases that shook the academy. University of California Press, Ewing, NY

Rosile GA (2007) Cheating: making it a teachable moment. J Manag Educ 31:582-613. https://doi.org/10.1177/ 1052562906289225

Shahghasemi E, Akhavan M (2015) Confessions of academic ghost authors: the Iranian experience. SAGE Open:1-7. https:// doi.org/10.1177/2158244015572262

Steel A (2017) Contract cheating: will students pay for serious criminal consequences? Alternative Law Journal 42:123-129. https://doi.org/10.1177/1037969X17710627

Tauginienè L, Gaižauskaitè I, Glendinning I, Kravjar J, Ojsteršek M, Ribeiro L, Odineca T, Marino F, Cosentino M, Sivasubramaniam S (2018) Glossary for academic integrity. ENAI Report 3G Accessed 10 Feb 2020. http://www. academicintegrity.eu/wp/wp-content/uploads/2018/02/GLOSSARY_final.pdf

Tauginienè L, Gaižauskaite I, Razi S, Glendinning I, Sivasubramaniam S, Marino F, Cosentino M, Anohina-Naumeca A, Kravjar J (2019) Enhancing the taxonomies relating to academic integrity and misconduct. J Acad Ethics 17:345-361. https://doi. org/10.1007/s10805-019-09342-4

Teixeira AAC, Rocha MF (2006) Academic cheating in Austria, Portugal, Romania and Spain: a comparative analysis. Res Comp Int Educ 1:198-209. https://doi.org/10.2304/rcie.2006.1.3.198

Thomas D (2017) Factors that explain academic dishonesty among university students in Thailand. Ethics Behav 27:140-154 https://doi.org/10.1080/10508422.2015.1131160

Trautner MN, Borland E (2013) Using the sociological imagination to teach about academic integrity. Teach Sociol 41:377388. https://doi.org/10.1177/0092055X13490750

Vilig K (2016) Kvalitativna istraživanja u psihologiji. Clio, Beograd

Vučković D (2010) Organizacija nastave na Studijskom programu za obrazovanje učitelja, [Organization of teaching at the Teacher Training Department]. Sociološka luča 4:146-172

Yin RK (1994) Case study research: design and methods. Sage, Beverly Hills, CA

\section{Publisher's Note}

Springer Nature remains neutral with regard to jurisdictional claims in published maps and institutional affiliations.

Ready to submit your research? Choose BMC and benefit from:
- fast, convenient online submission
- thorough peer review by experienced researchers in your field
- rapid publication on acceptance
- support for research data, including large and complex data types
- gold Open Access which fosters wider collaboration and increased citations
- maximum visibility for your research: over 100M website views per year
At BMC, research is always in progress.
Learn more biomedcentral.com/submissions

